\title{
The Willingness to Pay for the Ecological Compensation of Min River Basin-Based on the Survey of Chengdu 282 Households
}

\author{
Jimin Pan ${ }^{1}$, Weizhong Zeng ${ }^{1} \&$ Weikang Zhang ${ }^{1}$ \\ ${ }^{1}$ School of Economics \& Management, Sichuan Agricultural University, 211 Huimin Road, Wenjiang, Chengdu \\ 611130, China \\ Correspondence: Jimin Pan, School of Economics \& Management, Sichuan Agricultural University, 211 Huimin \\ Road, Wenjiang, Chengdu 611130, China. Tel: 86-155-2074-4035. E-mail: 281894747@qq.com
}

Received: February 25, 2012 Accepted: March 13, 2012 Online Published: April 16, 2012

doi:10.5539/ep.v1n2p14 URL: http://dx.doi.org/10.5539/ep.v1n2p14

This research is financed by Chinese Ministry of Education; the project is: research on the ecological compensation system and corresponding strategies of Min River in Sichuan (09YJAZH061)

\begin{abstract}
The mechanism of ecological compensation is considered as an effective way to solve the problems of the upstream and downstream river basins. This paper uses the Contingent Valuation Method (CVM) to investigate people's awareness of Min river basin's ecological compensation, and analyze the willingness to pay for the environmental improvement. Studies have shown that residents of Chengdu have a certain degree of eco-environmental awareness and willingness to pay, but the cognitive level of ecological protection isn't enough, and show a "government dependency" feature. $67.73 \%$ of the surveyed residents were willing to pay for the restoration of the ecological environment of Min river, and the average maximum willingness to pay was 63.47 Yuan / (person·year).
\end{abstract}

Keywords: minjiang river basin, willingness to pay, Contingent Valuation Method (CVM)

\section{Introduction}

Since the 1990s, Watershed ecological compensation widely concerned all sectors of the community, becoming a new kind of idea about environment protection and the coordinated development of the river's upstream and downstream basins. The mechanism of ecological compensation is considered an effective way to solve the problems of the upstream and downstream adjacent area, and the higher levels of economic development and ecological protection (Y. Z. Guan \& H. J. Zhu, 2003). In order to establish and perfect the mechanism of ecological compensation as an inevitable choice for a national and regional environmental management mode innovation the society and economy needs to develop to a certain extent. The western developed countries are ahead of China in the study of the theory of the mechanism for ecological compensation and the specific policy practice; in addition, they have accumulated rich experience. Foreign watershed ecological compensation practice has proved that (Pagiola et al., 2004; Dudley, 2005; Arnalds et al., 2003), watershed ecological compensation mechanism can straighten out the interest relationship between the upstream and downstream of the valley area to a certain extent, and it can also promote the harmonious development and protect the ecological environment of these areas effectively.

At present, many regions in our country have taken measures of ecological compensation dominated by the government, but the actual effect of policy is very poor (H. X. Zheng \& L. B. Zhang, 2006). The reason for this is that, the benefits of upstream and downstream valley have been dislocated, and the ecological services providers and services consumers did not establish a direct link. So, the ecological service is in short supply in a long period. A reasonable ecological compensation standard cannot be worked out because there is no effective evaluation about people's willingness of ecological compensation. At present, evaluation of the willingness to pay for the ecological services becomes one of the important means to study the ecological compensation mechanism of the river basin (H. X. Zheng \& L. B. Zhang, 2010). CVM was put forward and applied firstly by Davis in 1963, then it was widely applied in landscape protection, leisure, river biological diversity protection and other areas in developed countries and it became the main choice of evaluating the non-use values of the 
environment after its improvement in the theory and method (H. X. Zheng \& L. B. Zhang, 2010). In China, academics use this method generally to study the willingness to pay for environmental protection. Local studies include Zhao Jun's research on the willingness to pay for the river ecosystem service in the city of Shanghai, Liang Shuang and Feng Qing's study on the willingness to pay for environment protection and life pollution to the local farmers in the Beijing Miyun reservoir (W. J. Yu, 2011; S. Liang, 2005). However, the research on CVM is still in the initial stage of exploration.

In this paper, survey data from Chengdu was used to analyze the willingness to pay for ecological compensation and this was evaluated by means of 282 questionnaires designed according to the CVM method in order to provide a reference to develop an ecological compensation standard and implementation of the policy in the Min river basin.

\section{Research Area and Research Method}

\subsection{The Overview of the Study Area}

The Min River is the main tributary of the upper reaches of the Yangtze River. It is located in the central Sichuan province, originated in Songpan County, flows through into the Yangtze River in Yibin City north to south, and the main stream length is $735 \mathrm{~km}$. The Min River in the regions above Dujiangyan are referred as the upper reaches of Min River, covering the Song pan, Backwater, Maoxian County, Li County, Wenchuan and Dujiangyan. The upper reaches of the main stream have a total length of $340 \mathrm{~km}$.

The upper reaches of Min River area are rich in biological diversity and forest cover, providing a good ecosystem service for the downstream region. It is the "life water" for human survival, social and economic development and ecological environment protection of the West Sichuan Plain and Chengdu. In terms of the water, Min River is the largest tributary in the upper reaches of the Yangtze River, and it has abundant water resources. The upper reaches of Min river has had an annual flow $469 \mathrm{~m}^{3} / \mathrm{s}$, over the past years and the average annual runoff is $148 \times 108 \mathrm{~m}^{3} / \mathrm{s}$. Dujiangyan water is derived from Min river, and the water supply is as high as $70 \times 108 \mathrm{~m}^{3}$, which is the chief source of water for industry, agriculture and households in Chengdu $(\mathrm{H}$. Y. Zeng $\&$ B. Deng, 2009). From the perspective of water quality, the Chengdu water resources bulletin from 2007 and 2008 showed that the water quality from Min river to Dujiangyan is generally good, reaching Grade II, but when it exits from Chengdu the quality is very poor, worse than class V, due to the domestic, industrial pollution. Thus, there are serious problems about "protection in the upper reaches and pollution in the middle and lower reaches".

Economic growth is restricted in the upper reaches of Min River, so their economic condition is relatively low, while the ecological environment is very weak. The upper reaches of Min River make a significant contribution and great sacrifice to the ecological protection of the entire basin, therefore, they're the providers and losers of the ecosystem services, and consequently, they should be compensated. The fund for Constructing the mechanism of ecological compensation of Min river valley should be raised from these downstream areas and industry which has benefited. Chengdu, the biggest beneficiary, as well as an important polluter, has the responsibility to compensate for the upstream. Therefore, the study is representative and significant on Chengdu residents' willingness to pay for the value of restoring Watershed ecological environment.

\subsection{Research Methods and Design Questionnaires}

In this paper, a questionnaire-based survey was carried out in the benefited areas, in order to gain public awareness of watershed ecological compensation, willingness to pay, and the way of payment. Generally, we used Contingent Valuation Method (CVM) to construct an imaginary market to evaluate non-market willingness to pay for goods. CVM is a typical stated preference evaluation method. It is used in the imaginary market to investigate and ask directly people's Willingness to pay (WTP) for an ecological environment improvement or resources protection, or investigate the Willingness to accept environmental damage compensation (Willingness to accept compensation, WTA), finally, it estimates the value of environmental quality improvement or environmental quality loss on the base of people's WTP or WTA (Z. Q. Zhang \& Z. M. Xu, 2003). The questionnaire designing patterns of CVM method can be summarized in four different ways, such as iterative bidding game (IBG), open-ended (OE), payment card (PC) and dichotomous choice (DC). Iterative bidding game is the earliest research model, but it is seldom used at present. Open-ended questionnaire and payment card questionnaire are continuous; conversely, dichotomous choice questionnaire belongs to the discrete one. Open-ended questionnaire is usually used for pre-investigation, and the calculation of payment card questionnaire is simpler than payment card questionnaire. Among these four models, payment card questionnaire is easy to understand and has been applied widely in the developing world (H. X. Zheng \& L. B. Zhang, 2010). Hence, we used an open-ended questionnaire for pre- investigation, and then optimized the starting point and numerical intervals on the basis of the pre- survey; finally, formal investigations were carried out with the 
improved payment card.

The questionnaire was divided into three parts. The first part covered the personal information of the respondents, aiming to know their age, gender, education, income, occupation and other socio-economic information. The second part was a survey of resident's awareness of the ecological environment, including the residents understanding of the ecological state of the environment on the Min River, the preference for environmental protection and economic development and understanding of the main environmental responsibility. The third part was the investigation of willingness to pay for ecological compensation of Chengdu residents in Min valley, and the core issue was "whether your family is willing to pay a fee every year, in order to improve the quality of ecological environment in Min River?" If the respondents said "Yes", the payment card was presented asking the amount that they would pay, and further investigating the method of payment. If the answer was "No", the reasons for this were explored. This information was used to assess the Willingness to pay for the value of restoring Watershed ecological environment to the upper reaches, as well as the method of payment.

\section{The Statistical Analysis of Survey Results and the Valuation of Willingness to Pay}

\subsection{The Implementation of the Survey}

This survey was conducted from May to August 2011 and this included the pre-survey and the formal investigation. The pre-survey used an open-ended questionnaire, distributing 80 questionnaires and 74 valid questionnaires were received. According to the results of pre-survey, we used optimized payment card questionnaire to conduct formal investigations. This questionnaire survey was developed by students from the research group of Sichuan Agricultural University of Economics and Management during the holidays, and 300 questionnaires were launched, 282 valid ones were received, and the response rate was $94 \%$. The sample scope of the formal investigation included Wenjiang, Jinniu, Jinjiang District, Chongzhou City, Xinjin County, Dujiangyan City, as well as counties that Min river and its tributaries flow through. The number of samples was determined in proportion to the number of households in each county and district in 2010. Questionnaires were distributed using the random sampling method, and the investigated area covered the Min valley. Hence, this survey questionnaire meets the extensive requirements of CVM.

From the gender of the respondents, there were 164 males, accounting for $58.16 \%$ of the total number of the sample, 118 women, and accounting for $41.84 \%$. Since males have decision-making power in the family, the proportion of men was slightly higher. In terms of age, the youngest respondents were 18 years old, and the oldest were 76; and the average age was 35.69 years with 203 of the respondents in the age range of 25 to 55 years. From the view point of educational background, respondents were relatively well educated. 179 had high school and undergraduate education, accounting for $63.48 \%$ of the total number of the sample. From the view point of personal income, they account for $11.16 \%$ of the total sample whose income is less than 10,000 RMB, and account for $67.76 \%$ between 10,000 and 30,000 RMB, and account for $21.08 \%$ over 30,000 RMB. Workers in enterprises and public institutions took up a large proportion of $49.5 \%$, followed by farmers, civil servants and students.

\subsection{The Cognitive Degree of the Ecological Environment of Residents}

Cognition of the Minjiang's ecological environment: Assessment of residents' enthusiasm of their participation in environmental protection can be affected by the feelings of the surrounding environment. The results of the survey showed that the majority of residents expressed concern on the ecological environment and only $3.19 \%$ of the respondents say they are not concerned about the ecological environment problems. From the aspect of the awareness of the importance of the ecological environment on the upper reaches of Min river, $62.41 \%$ of the respondents believe that the ecological environment is very important, and $8.01 \%$ believe that Min's ecological environment has deteriorated in the past two decades, while, $71.28 \%$ of the respondents think that the surrounding environment has improved over the past five years. This indicates that the effects of the national implementation of watershed environmental protection projects have been realized in recent years, and the ecological environment has been improved, as a result, downstream residents can benefit. From the view point of investment in the upstream areas to protect the ecological environment, only $6.38 \%$ of the respondents said they understood the ecological policy of the upstream region well, $36.52 \%$ said they do not quite understand or do not understand at all. It can be seen from above, residents in survey area have some awareness of the ecological environment and ecological compensation, but their awareness of ecological protection is not very good.

Preference for environmental protection and economic development: Assessment of the understanding of the economic development and the importance of environmental protection showed that $15.96 \%$ of the residents think that economic development is more important, however, $23.4 \%$ consider protecting environment more important, and $60.64 \%$ endorsed that environmental protection and economic development should be carried out 
at the same time. Thus, people increasingly expect to achieve a balance between economic development and environmental protection.

Awareness of environmental protection subject: Assessment of people's initiative in participating in environmental protection will be affected greatly by their awareness of environmental protection subject. The survey shows that $58.16 \%$ of the respondents believe that the environmental protection is the responsibility of the government; $21.27 \%$ consider corporate or individuals to be responsible for environmental pollution; only $20.57 \%$ believe that every citizen should be responsible for it. The investigation proves that, the interviewees have the habit of dependence on governments for environmental protection.

\subsection{Analysis of Willingness to Pay for Ecological Compensation}

Firstly the survey asked respondents if they believe the upper reaches of Min River have paid price for environmental protection, and whether they should be compensated and if they will be willing to pay. For residents whose answer was "yes", the maximum amount they were willing to pay each year, as well as the method of payment was requested. According to the results of the survey, $90.07 \%$ of the residents believe that the upper reaches of Min River had made a sacrifice for ecological environmental protection and $91.84 \%$ thought that they need to compensate for the upstream areas. Since the two figures were almost equal, thus it was concuded that people are willing to compensate if they realize that the upstream region have paid price for protecting the local ecology. According to the interviewees' willingness to pay, only $67.73 \%$ of the respondents said "yes", which was far below that necessary to compensate. From the above it can be seen that, the respondents' willingness to compensate will be weakened when they're asked to pay for ecological environment of the Min river basin. It reflects that there's deviation on people's awareness of environmental protection and the chances of "free rider".

From this survey, they were 191 respondents willing to pay for the protection of the ecological environment of the Min river basin (WTP > 0), accounting for $67.73 \%$ of the total sample. On the method of payment, the selection list included donations, paying more utilities, participating in voluntary labor, ecological protection tax and buying lottery for environmental protection. The survey shows that donation and paying more for utilities become the main choice, accounting for $30.89 \%$ and $27.75 \%$ respectively, and $14.66 \%$ of residents choose to do voluntary labor, and only $26.7 \%$ choose ecotax and environmental lottery. This reflects that people prefer the traditional methods of payment. The two new ways of ecotax and environmental lottery are only accepted by people who have higher environmental awareness (Table 1).

Table 1. Statistics of the Chengdu residents' willingness to pay in Minjiang valley

\begin{tabular}{lccc}
\hline Items & Options & Sample size (person) & Proportion (\%) \\
\hline \multirow{2}{*}{ Willingness to pay } & Yes & 191 & 67.73 \\
& No & 91 & 32.27 \\
\hline \multirow{4}{*}{ Reasons for not willing } & X1 & 38 & 41.76 \\
to pay & X2 & 6 & 6.59 \\
& X3 & 20 & 21.98 \\
& X4 & 17 & 18.68 \\
& X5 & 3 & 3.3 \\
& X6 & 7 & 7.69 \\
The way of payment & X7 & 59 & 30.89 \\
& X8 & 53 & 27.75 \\
& X9 & 28 & 14.66 \\
& X10 & 42 & 21.99 \\
& X11 & 9 & 4.71 \\
\hline
\end{tabular}

X1- They think that funds should be raised by the government, X2- The upper reaches are responsible for the ecological degradation, X3- Having no ability to pay, due to low family income, X4- Do not believe that the 
compensation funds can be used well, X5- Not interested in the ecological environment of Min river, X6Environmental change on their own has little effect, X7- Donation, X8- Paying more for utilities, X9Participating in voluntary labor, X10- ecotax, X11- Buying environmental lottery.

91 respondents were not willing to pay $(\mathrm{WTP}=0)$, accounting for $32.27 \%$ of the total sample. The three major reasons for this were: people have no ability to pay, due to low family income; second, they do not agree there are responsible, because they think that funds should be raised by the government or the upper reaches, not the individual in the middle and lower reaches. Thirdly, they were worried that compensation funds are not earmarked, thus, the environmental programs can not achieve the desired effect.

We obtained the frequency distribution of willingness to pay by sorting the statistics of respondents' willingness to pay (Table 2). Respondents were willing to pay 1000 Yuan / year as the maximum amount, and the minimum amount was 5 Yuan / year, and the payment amount below 100 Yuan (including 100 Yuan) accounted for $69.11 \%$ of the respondents in the sample. At the same time, the frequency was higher for those willing to pay 50 Yuan, 100 Yuan, 200 Yuan, as there were 31 people, 40 people, and 25 people respectively. Those willing to pay 100 Yuan accounted for $20.94 \%$ of the sample and had the highest frequency. From the chart of the frequency distribution WTP, the distribution curve was not smooth nor a normal distribution. This shows that willingness to pay fluctuates greatly (Figure 1).

Table 2. Statistics of the frequency distribution of the Willingness to pay for

\begin{tabular}{cccccc}
\hline $\begin{array}{c}\text { Willingness } \\
\text { to pay (RMB) }\end{array}$ & $\begin{array}{c}\text { Frequency } \\
\text { (person) }\end{array}$ & $\begin{array}{c}\text { Positive } \\
\text { frequency of the } \\
\text { willingness to } \\
\text { pay (\%) }\end{array}$ & $\begin{array}{c}\text { Positive cumulative } \\
\text { frequency of the } \\
\text { willingness to pay (\%) }\end{array}$ & $\begin{array}{c}\text { Total frequency } \\
\text { of the willingness } \\
\text { to pay (\%) }\end{array}$ & $\begin{array}{c}\text { Cumulative } \\
\text { frequency } \\
(\%)\end{array}$ \\
\hline 0 & 91 & & 3.66 & 32.27 & 32.27 \\
5 & 7 & 3.66 & 10.99 & 2.48 & 34.75 \\
10 & 14 & 7.33 & 22.51 & 4.96 & 39.72 \\
20 & 22 & 11.52 & 26.18 & 7.80 & 47.52 \\
30 & 7 & 3.66 & 27.75 & 2.48 & 50.00 \\
40 & 3 & 1.57 & 43.98 & 1.06 & 51.06 \\
50 & 31 & 16.23 & 45.55 & 10.99 & 62.06 \\
60 & 3 & 1.57 & 48.17 & 1.06 & 63.12 \\
80 & 5 & 2.62 & 69.11 & 1.77 & 64.89 \\
100 & 40 & 20.94 & 73.82 & 14.18 & 79.08 \\
150 & 9 & 4.71 & 86.91 & 3.19 & 82.27 \\
200 & 25 & 13.09 & 89.01 & 8.87 & 91.13 \\
300 & 4 & 2.09 & 90.58 & 1.42 & 92.55 \\
400 & 3 & 1.57 & 97.91 & 1.06 & 93.62 \\
500 & 14 & 7.33 & 98.43 & 4.96 & 98.58 \\
600 & 1 & 0.52 & 100.00 & 0.35 & 98.94 \\
1000 & 3 & 1.57 & & 1.06 & 100.00 \\
\hline Total & 282 & 100 & & & \\
\hline & & & & & \\
\hline
\end{tabular}




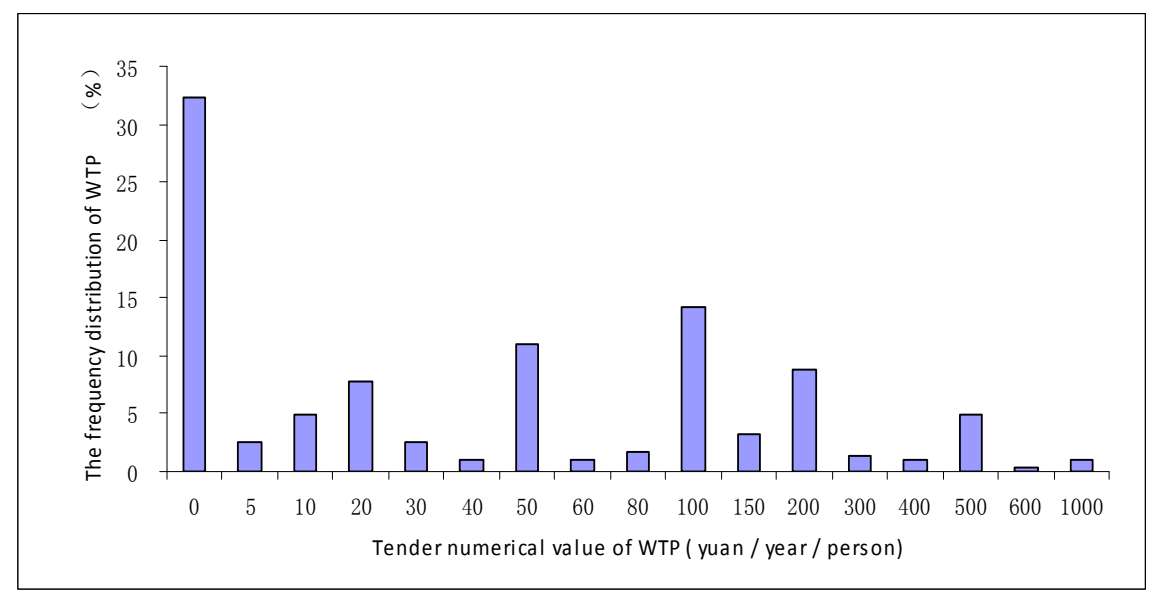

Figure 1. Frequency distribution of Willingness to pay

The frequency distribution was combined with Hanemann's WTP mathematical expectation formula adjusted using Spike's model; was used to obtain the the average maximum willingness to pay of Chengdu residents (Hanemann, 1994; Kritrom, 1991). Based on the frequency distribution of willingness to pay, we calculated the positive average willingness by using the mathematical expectation formula of the discrete variables:

$$
E(W T P>0)=\sum_{i=1}^{n} A_{i} P_{i}
$$

Where $A_{i}$ is the tender numerical value of WTP, and $\mathrm{P}_{i}$ is the amount of probability respondents to choose, and $\mathrm{n}$ is the number of alternative tender, and $\mathrm{n}=16$, so $\mathrm{E}$ (WTP) positive is calculated as 93.71 Yuan / (person year). The exact average willingness need to be adjusted using Spike model, because the WTP of $32.27 \%$ of the sample is zero, and Eq. (1) was amended as:

$$
E(W T P)=E(W T P>0) \cdot\left(1-W T P R_{0}\right)
$$

Where $W T P R_{0}$ is the ratio of people who don't want to pay. It is calculated that $E(W T P)$ is 63.47 Yuan (person-year) for Chengdu residents for the value of restoring the ecological environment of Min river. Compared to the recent findings by other local scholars, Yu Wenjin has obtained that the residents are willing to pay 19.19 RMB per month for restoring the ecological environment of the Taihu Lake Basin, Wuxi City and Cai Zhijian shows that residents of Nanjing are willing to pay 100.66 Yuan / (household. year) for recovering the water quality of Yangtze River (W. J. Yu, 2011; Z. J. CAI, 2007). After the unit conversion, we can see that Chengdu residents' willingness to pay is slightly lower than that in other regions highlighted above. So the result is reasonable, considering the level of local economic development.

\section{Conclusions and Recommendations}

From the above analysis, we can obtain the following conclusions and policy implications:

1) Residents of Chengdu have has some ecological environmental consciousness and willingness to pay, but the cognitive level of ecological protection isn't enough, and shows a "government dependence" feature. Therefore, we need to strengthen the education and publicity of ecological environment, in order to improve residents' familiarity and the cognitive level, making everyone know the environmental philosophy "who profits, who pays".

2) $67.73 \%$ of the surveyed residents are willing to pay for the restoration of the ecological environment of Min river, and the average maximum willingness to pay was 63.47 Yuan /(person-year) which is lower comparing to other local study results. Accelerating the pace of economic growth and increasing residents' income is the fundamental way of improving the residents' willingness to pay for the ecological compensation of Min valley.

3) Currently, eco-tax in foreign countries has been widely used in the field of ecological protection and it will be the most important source of funds. From the survey, people prefer the traditional way to pay a fee, for example, donation and paying more for utilities, e.t.c. As a result of inadequate publicity, eco-tax as a new way is accepted by only a few people, therefore strengthening advocacy and accelerating the legislation of ecological compensation is crucial to the river basin's environmental protection.

4) The reason why residents refused to pay for ecological compensation was people were concerned that the 
compensation funds were not going to be specifically used for protecting environment. Thus, rational and equitable standards should be defined; in addition, we should supervise the ecological compensation funds well to use it transparently.

\section{References}

Arnalds, O., \& Barkarson, B. H. (2003). Soil erosion and land use policy in Iceland in relation to sheep grazing and government subsidies. Environmental Science \& Policy, 6, 105-113. http://dx.doi.org/10.1016/S1462-9011(02)00115-6

Cai, Z. J., \& Zhang, W. W. (2007). Willingness to Pay for Water Quality Improvement of Yangtze River and Payment Mechanism in Nanjing Area. Ecological Environment, 2, 116-119.

Dudley, R. G. (2005). A generic look at payments for environmental services: Plan or scam. The 23rd International System Dynamics Conference, Boston, USA.

Guan, Y. Z., \& Zhu, H. J. (2003). Theory and practice of the regional ecological environment's construction. China Environmental Science Press.

Hanemann, W. M. (1994). Valuing the Environment through Contingent Valuation. Journal of Economic Perspectives, 4, 19-25. http://dx.doi.org/10.1257/jep.8.4.19

Kritrom, B. (1991). Spike models in contingent valuation. American Journal of Agricultural Economics, 4, 1013-1023.

Liang, S., \& Jiang, N. (2005). Analysis of farmers' willingness to pay and its influence factor of urban water sources. -- basing on Mi Yun. China's Rural Economy, 2, 55-60.

Pagiola, S., Agostin, A., \& Platais, G. (2004). Can payments for environmental services help reduce poverty? An exploration of the issues and the evidence to date from Latin America. World Development, 2, 237-253.

Yu, W. J., Xie, J., \& Zou, X. Q. (2011). CVM for Taihu Lake based on ecological functions of wetlands restoration and ability to pay and willingness to pay studies. Acta Ecologica Sinica, 23, 7271-7278.

Zeng, H. Y., Deng, B., \& Li, Y. (2009). Influence on Wenchuan Earthquake on Water Resources and Water Environment in the Upper Reaches of the Min River. Journal of Sichuan Normal University (Natural Science), 1, 134-138.

Zhang, Z. Q., Xu, Z. M., \& Cheng, G. D. (2003). The Updated Development and Application of Contingent Valution Method (CVM). Advance In Earth sciences, 3, 454-463.

Zheng, H. X., \& Zhang, L. B. (2006). Ecological Compensation Mechanism and Policy Recommendations in Jinhua River Basin. Resources Science, 9, 30-35.

Zheng, H. X., \& Zhang, L. B. (2010). Analysis of the People's Willingness to Pay for Environmental Services Compensation and Its Influence Factors in the Jinhua River Basin. Resources Science, 4, 761-767. 